\title{
Aberrant right subclavian artery and arterioesophageal fistula
}

\author{
Nathan D. Peffley, MD (D) Marci B. Pepper, MD • Erica D. Wittwer, MD, PhD • \\ Joseph A. Dearani, MD
}

Received: 10 September 2020/Revised: 8 October 2020/Accepted: 18 October 2020/Published online: 10 November 2020

(C) Canadian Anesthesiologists' Society 2020

Five weeks after aortic and pulmonary valve replacement and prolonged postoperative intensive care, a 40-yr-old woman developed massive upper gastrointestinal bleeding. At the time, she had respiratory failure requiring tracheostomy and she also had bowel ischemia due to a low cardiac output state requiring partial colectomy and nasogastric tube decompression. To identify the source of bleeding, upper endoscopy was attempted, but quickly aborted given prohibitive bleeding. Computed tomography showed an aberrant right subclavian artery, a vascular anomaly wherein this vessel arises from the descending aorta distal to the left subclavian artery (Figure, panel A) and travels posterior to the trachea and esophagus (Figure, panel B). An aortogram with selective cannulation of the aberrant subclavian artery showed extravasation into an arterioesophageal fistula. An endovascular stent was placed to occlude the fistula and this successfully resolved the bleeding (Figure, panel A).

Aberrant right subclavian artery is the most common aortic arch anomaly with estimated prevalence up to $2.5 \%{ }^{1}$ Although often asymptomatic, symptoms are usually manifestations of esophageal or tracheal compression by the vessel. ${ }^{2}$ The proximity of these structures and recognition of potential iatrogenic compression perioperatively is important for prevention and diagnosis of resultant complications in this patient population. Although rare, there are several reports of patients with this anomaly developing an arterioesophageal fistula attributed to endotracheal- or nasogastric tube-induced pressure necrosis. ${ }^{3}$ Perioperatively, esophageal

N. D. Peffley, MD $(\bowtie) \cdot$ M. B. Pepper, MD

E. D. Wittwer, MD, PhD

Mayo Clinic Department of Anesthesiology and Perioperative

Medicine, Rochester, MN, USA

e-mail: Peffley.Nathan@mayo.edu

J. A. Dearani, MD

Mayo Clinic Department of Cardiovascular Surgery, Rochester,

MN, USA

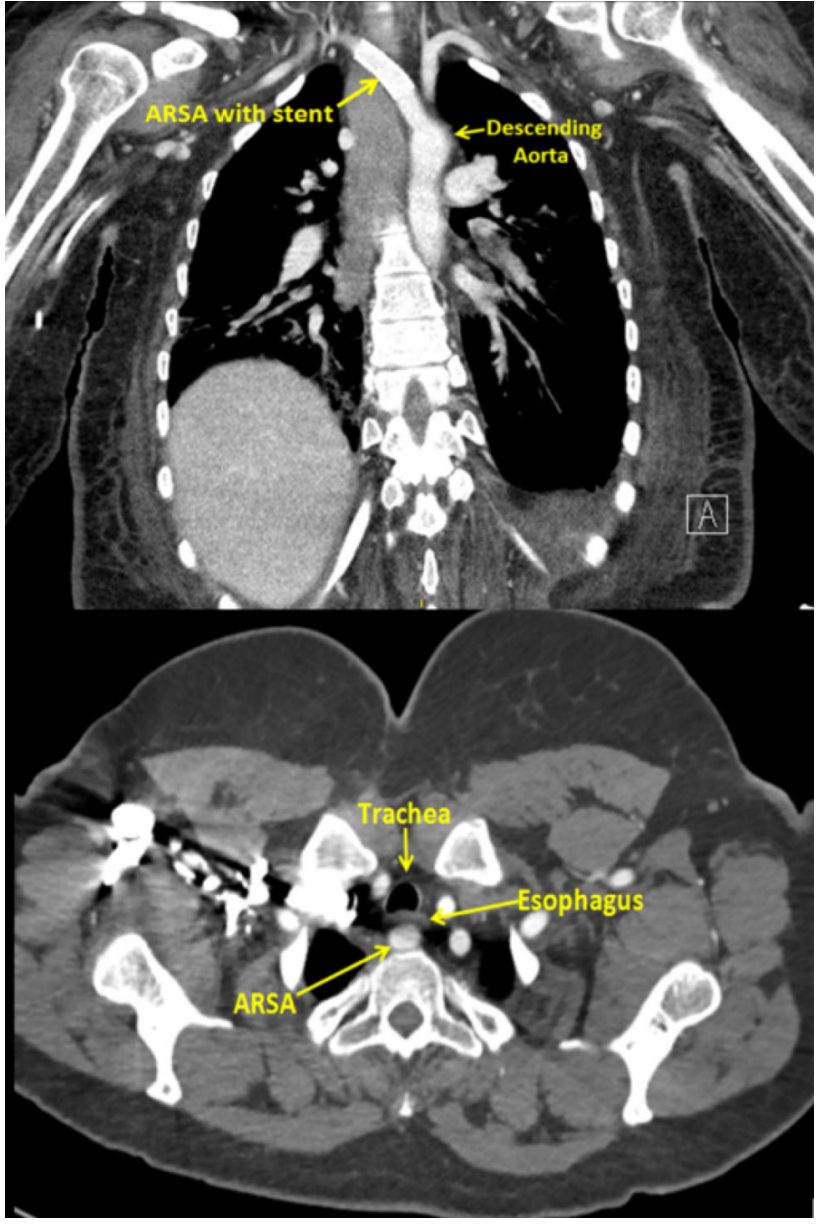

Figure Computed tomography scans (Panel A - coronal plane; Panel $\mathrm{B}-$ axial plane) of aberrant right subclavian arteryARSA = aberrant right subclavian artery

instrumentation should be done with caution or avoided, if possible. Anesthesiologists should be mindful that tracheal intubation and esophageal instrumentation may compress the esophagus, potentially leading to arterioesophageal fistula formation. Clinicians should 
consider this etiology of gastrointestinal bleeding to avoid delayed treatment.

\section{Disclosures None.}

\section{Funding statement None.}

Editorial responsibility This submission was handled by Dr. Philip M. Jones, Associate Editor, Canadian Journal of Anesthesia.

\section{References}

1. Polednak AP. Prevalence of the aberrant right subclavian artery reported in a published systematic review of cadaveric studies: the impact of an outlier. Clin Anat 2017; 30: 1024-8.

2. Gadhinglajkar SV, Sreedhar $R$, Unnikrishnan $M$, Varma $R$. Surgery for dysphagia lusoria caused by right aberrant subclavian artery: anesthesia perspective. J Cardiothorac Vasc Anesth 2005; 19: 86-9.

3. Millar A, Rostom A, Rasuli P, Saloojee N. Upper gastrointestinal bleeding secondary to an aberrant right subclavian arteryesophageal fistula: a case report and review of the literature. Can J Gastroenterol 2007; 21: 389-92.

Publisher's Note Springer Nature remains neutral with regard to jurisdictional claims in published maps and institutional affiliations. 